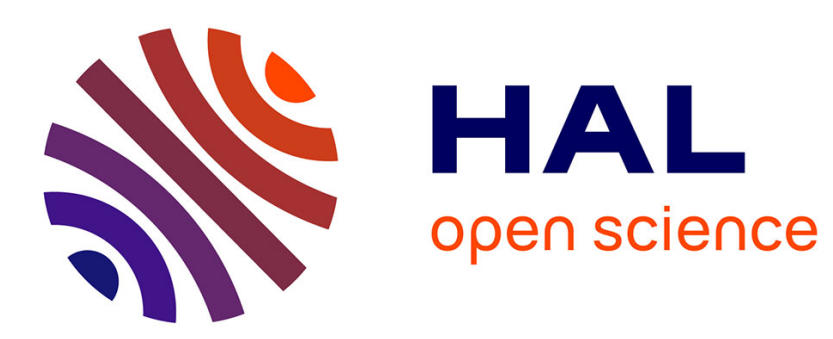

\title{
Experimental and Thermodynamic Study of the Microstructure of Tantalum containing Nickel-base Alloys at High Temperature
}

\author{
P. Berthod, L. Aranda, C Vébert, S. Michon
}

\section{- To cite this version:}

P. Berthod, L. Aranda, C Vébert, S. Michon. Experimental and Thermodynamic Study of the Microstructure of Tantalum containing Nickel-base Alloys at High Temperature. Calphad, 2004, 10.1016/j.calphad.2004.07.005 . hal-02406112

\section{HAL Id: hal-02406112 \\ https://hal.science/hal-02406112}

Submitted on 12 Dec 2019

HAL is a multi-disciplinary open access archive for the deposit and dissemination of scientific research documents, whether they are published or not. The documents may come from teaching and research institutions in France or abroad, or from public or private research centers.
L'archive ouverte pluridisciplinaire HAL, est destinée au dépôt et à la diffusion de documents scientifiques de niveau recherche, publiés ou non, émanant des établissements d'enseignement et de recherche français ou étrangers, des laboratoires publics ou privés. 


\title{
Experimental and Thermodynamic Study of the Microstructure of Tantalum containing Nickel-base Alloys at High Temperature
}

\author{
P. Berthod*, L. Aranda, C. Vébert, S. Michon \\ Laboratoire de Chimie du Solide Minéral (UMR 7555), Université Henri Poincaré \\ BP 239, 54506 Vandoeuvre-lès-Nancy - France \\ * Corresponding author's e-mail: patrice.berthod@ centraliens-lille.org \\ Post-print version of the article Calphad, Vol. 28, pp. 159-166 (2004); doi:10.1016/j.calphad.2004.07.005
}

\begin{abstract}
Experiments and thermodynamic calculations were performed on three nickel-base alloys containing chromium, carbon and tantalum. Solidus and liquidus temperatures, natures and surface fractions of the carbides after an exposure for 100 hours at $1000^{\circ} \mathrm{C}, 1100^{\circ} \mathrm{C}$ and $1200^{\circ} \mathrm{C}$, were determined for each alloy. These results are compared with calculated results, using a thermodynamic database. A good agreement was generally found for the solidus temperatures but less for the liquidus ones. For alloys containing chromium carbides alone, carbides fractions and matrix compositions correspond to calculation results. But the presence of tantalum carbides in the third alloy was not predicted by calculations.
\end{abstract}

\section{Introduction}

Superalloys are used at high temperature under mechanical stresses. Many of the superalloys are reinforced with carbides such as chromium carbides (of the $\mathrm{M}_{23} \mathrm{C}_{6}$ and $\mathrm{M}_{7} \mathrm{C}_{3}$ types) and $\mathrm{MC}$ carbides. Tensile strength and creep resistance largely depend on the volume fraction of these carbides and on their possible evolution during a long exposure at high temperature. It could be very useful to own a thermodynamic calculation tool, software and database, to predict quantitative data about the microstructure at the working temperature. The database must be especially defined for the studied superalloys family and, before being really used, its results need to be compared to reality.

The topic of this work is first to provide, about the equilibrium state of nickel base superalloys strengthened by chromium and tantalum carbides at different high temperatures, some metallurgical results that can be later used for database evaluations. A special attention was given to several characteristics which are important for either the alloy fabrication (castability : solidification temperature range), or mechanical properties (alloy refractoriness, type and volume fraction of the strengthening phases). Second, these metallurgical data are used to estimate, on three Ni-Cr-C-Ta alloys, the accuracy of a first thermodynamic database especially built for cobalt-base alloys strengthened by tantalum carbides

\section{Experimental Method}

Table 1 displays the chemical composition and designation of the three studied nickel-base alloys. The chromium, carbon and tantalum contents were chosen so that they are representative of carbides strengthened nickel-base superalloys that are used in the aeronautical industry or in high temperature industrial processes $[1,2]$. The obtained compositions slightly differ from the targeted ones since a small part of the most reactive element (Ta) was lost during the preparation. 
Table 1 Chemical Compositions of the Studied Nickel-Base Alloys (in weight percent)

\begin{tabular}{|c|c|c|c|c|c|c|c|c|}
\hline \multirow{2}{*}{$\%_{\text {wt }}$} & \multicolumn{4}{|c|}{ Targeted compositions } & \multicolumn{3}{c|}{ Obtained compositions (EDS) } \\
\cline { 2 - 9 } & $\mathrm{Ni}$ & $\mathrm{Cr}$ & $\mathrm{C}$ & $\mathrm{Ta}$ & $\mathbf{N i}$ & $\mathbf{C r}$ & $\mathbf{C}$ & Ta \\
\hline Alloy A & Bal. & 30 & 0.2 & 3 & Bal. & $\mathbf{3 0 . 9}$ & $\cong \mathbf{0 . 2}$ & $\mathbf{2 . 0 4}$ \\
\hline Alloy B & Bal. & 30 & 0.4 & 3 & Bal. & $\mathbf{3 1 . 9}$ & $\cong \mathbf{0 . 4}$ & $\mathbf{2 . 6 6}$ \\
\hline Alloy C & Bal. & 30 & 0.4 & 6 & Bal. & $\mathbf{3 0 . 6}$ & $\cong \mathbf{0 . 4}$ & $\mathbf{5 . 4 4}$ \\
\hline
\end{tabular}

The three alloys were prepared, under argon gas, from the pure elements (>99\%, Alfa Aesar) using a high frequency induction furnace in a water-cooled copper crucible (CELES). After melting, the alloys solidified in the copper crucible itself, taking the form of a compact ingot of nearly $100 \mathrm{~g}$.

All the samples were taken from the bulk of these ingots. The volume of a sample for determination of the solidus and liquidus temperatures was approximately $10 \mathrm{~mm}^{3}$ while the volume of samples that will be exposed at high temperature to observe its microstructure was about $250 \mathrm{~mm}^{3}$.

\section{Thermal Analysis and High Temperature Exposures}

Differential Scanning Calorimetry analysis were carried out for the three alloys to determine their solidus and liquidus temperatures. The heating rate was $20{ }^{\circ} \mathrm{C} / \mathrm{min}$ up to $1200{ }^{\circ} \mathrm{C}$, then $5{ }^{\circ} \mathrm{C} / \mathrm{min}$ up to $1470{ }^{\circ} \mathrm{C}$. It is followed by a cooling at $5{ }^{\circ} \mathrm{C} / \mathrm{min}$ down to $1200^{\circ} \mathrm{C}$, then $20^{\circ} \mathrm{C} / \mathrm{min}$ down to room temperature. Solidus and liquidus temperatures are measured on both the heating and the cooling curve. The average value of the two was considered.

Three samples of each alloy were exposed to three different temperatures $\left(1000,1100\right.$ and $\left.1200{ }^{\circ} \mathrm{C}\right)$, for 100 hours to be sure to reach the equilibrium state. Exposures were performed in the high temperature furnace of a TGA-92 Setaram thermo-balance, with a heating rate of $20^{\circ} \mathrm{C} / \mathrm{min}$ and a cooling rate of $10{ }^{\circ} \mathrm{C} / \mathrm{min}$. After high temperature exposure, the samples for microstructure observations were cut in two parts, using an Accutom-2 saw equipped with a diamond blade. They were then embedded in a cold resin (Araldite CY230 +Strengthener Escil HY956), and polished first with $\mathrm{SiC}$ paper from 80 to 1200 grid under water and finished with $6 \mu \mathrm{m}$ and $3 \mu \mathrm{m}$ diamond pastes.

\section{Microstructure Characterization and Chemical Composition Determinations}

The microstructures of the alloys, as cast and after each high temperature exposure, were observed using a XL30 Philips Scanning Electron Microscope (SEM) mainly in the Back Scattered Electrons (BSE) and under an acceleration voltage of $20 \mathrm{kV}$. For each alloy five pictures were taken using the SEM in BSE mode, at a magnification of $\mathrm{x} 500$ on different locations randomly selected (areas of $0.04 \mathrm{~mm}^{2}$ ). The BSE mode allowed the separation of gray matrix (medium average atomic number), dark chromium carbides (low atomic number) and white tantalum carbides (high atomic number). Thereafter the surface fractions of all the phases were measured using the AnalySIS software of Soft Imaging Systems GMBH. Each surface fraction given hereafter is the average of five measures. These surface fractions were considered as being equals to the volume fractions.

The alloy general chemical compositions were determined using the Energy Dispersion Spectrometry (EDS) apparatus adapted on the SEM. Compositions were measured on five randomly selected areas, each of about $0.04 \mathrm{~mm}^{2}$, and the general composition was considered to be the average of the five previous ones. The matrix compositions were also determined using EDS, but in a spot mode. The carbon content was not analyzed because of its low contents and its small atomic weight. Then, only the chromium and tantalum contents are hereafter given, as the average of five EDS analysis spot measures in different locations in the matrix. The nature of the carbides were determined by Wavelength Dispersion Spectrometry (WDS) with a CAMECA SX100 microprobe.

\section{Thermodynamic Modeling}

Calculations were carried out for the alloys, using the Thermo-Calc software [3]. The database used is SSOL (SGTE) [4] that already contained the descriptions of the binary and ternary systems C-Cr, C-Ni, Cr-Ni and $\mathrm{C}-\mathrm{Cr}-\mathrm{Ni}$. This database was supplemented with the descriptions of new systems (Ta-C, Ta-Ni, Ta-Cr, Ni-CrTa) [5 to 8]. The following quantities were of interest:

- the solidus temperature and the liquidus temperature, 
- the phases present at $1000{ }^{\circ} \mathrm{C}, 1100{ }^{\circ} \mathrm{C}$ and $1200{ }^{\circ} \mathrm{C}$ and their mass fractions

- the chemical composition of the matrix.

The mass fraction values obtained from Thermo-Calc were converted into volume fraction values according to the equation (1). The $\mathrm{f}_{\mathrm{vol}}\left(\varphi_{\mathrm{j}}\right), \mathrm{f}_{\mathrm{w}}\left(\varphi_{\mathrm{j}}\right)$ and $\rho_{\mathrm{j}}$ are the volume fraction, weight fraction and density of

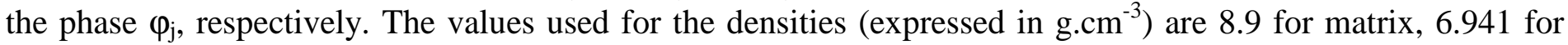
$\mathrm{Cr}_{7} \mathrm{C}_{3}, 6.953$ for $\mathrm{Cr}_{23} \mathrm{C}_{6}$ and 14.5 for $\mathrm{TaC}$ [9].

$$
\mathrm{f}_{\mathrm{vol}}\left(\varphi_{\mathrm{j}}\right)=\left(\frac{\mathrm{f}_{\mathrm{w}}\left(\varphi_{\mathrm{j}}\right)}{\rho_{\varphi_{\mathrm{j}}}}\right) / \sum_{\mathrm{i}}\left(\frac{\mathrm{f}_{\mathrm{w}}\left(\varphi_{\mathrm{i}}\right)}{\rho_{\varphi_{\mathrm{i}}}}\right)
$$

\section{Results}

\section{Initial Microstructures}

Figure 1 shows the initial microstructures of the three nickel-base alloys as cast. Primary carbides, that formed during solidification, can be seen in grain boundaries. They are of two types, chromium carbides (dark) and tantalum carbides (white) and in all cases they form an eutectic with the matrix. There are more carbides in Alloy B and Alloy $\mathrm{C}$ than in Alloy A due to different carbon contents of the alloys. Alloy C has more TaC carbides since it contains more tantalum than the others.

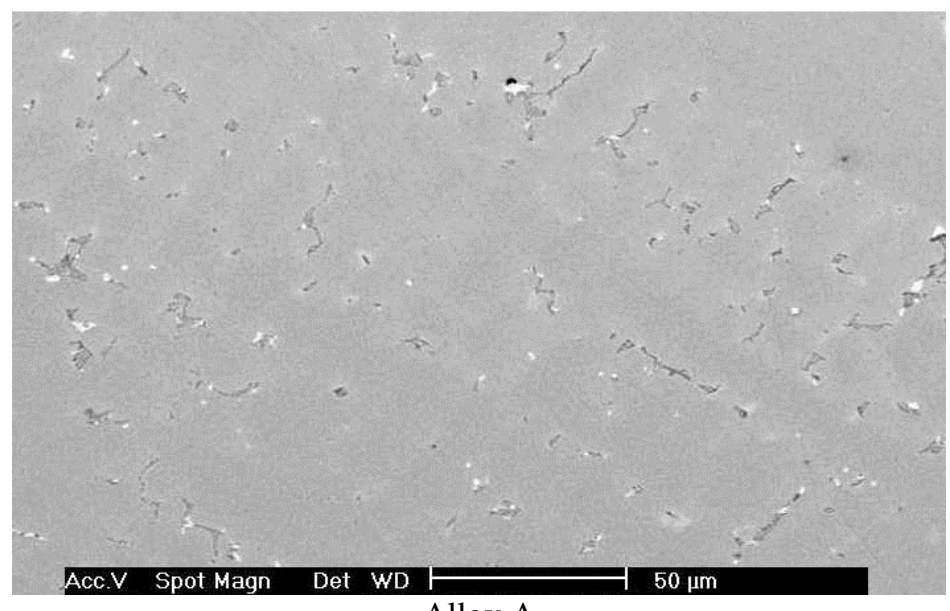

Alloy A

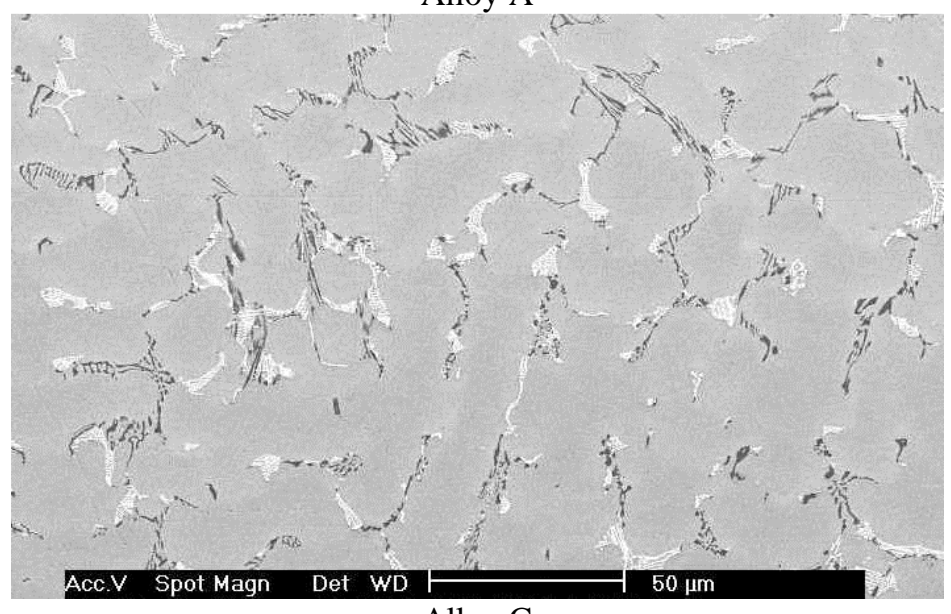

Alloy C

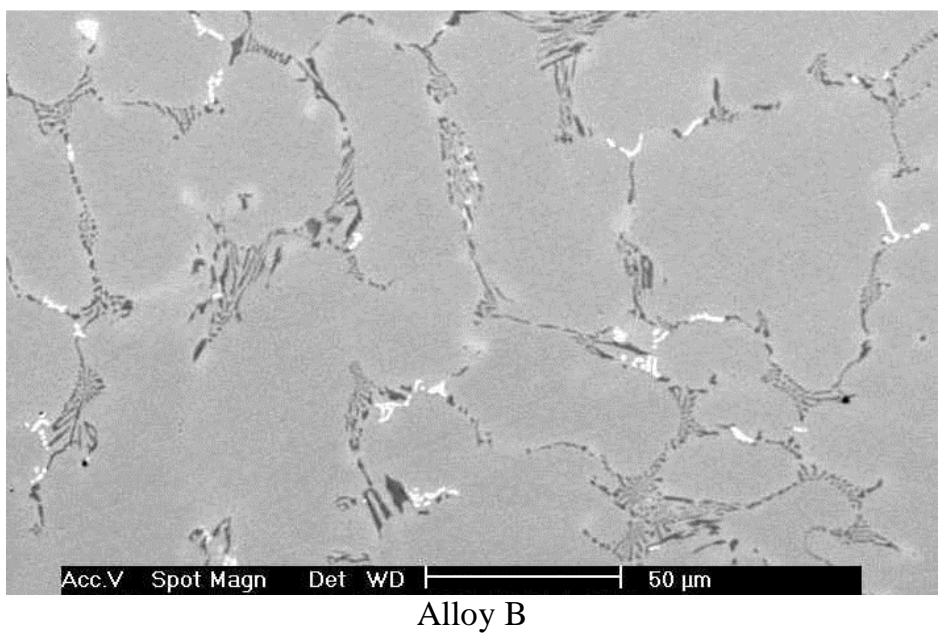

Figure 1 Initial microstructures of the three nickel-base alloys (BSE images) :

Face centered cubic nickel matrix (in gray)

Chromium carbides (in black)

Tantalum carbides (in white)

\section{Thermal Analysis Results}

Differential Scanning Calorimetry experiments were performed for the three alloys. Temperatures of solidus and liquidus were determined using both the heating and the cooling curves. Temperatures of the 
beginning and the end of the endothermic phenomena (heating) were systematically higher than the beginning and the end of the exothermic one (cooling), an hysteresis phenomena due to kinetic reasons. Then, a good approximation for solidus and liquidus temperatures, is to take the average value of the heating and cooling. Figure 2 displays the example of a DSC result obtained on Alloy B with two types of curves : heat flow versus time (associated with the temperature evolution law) and heat flow versus temperature. Table 2 displays the measured values of solidus and liquidus temperatures for the three alloys.

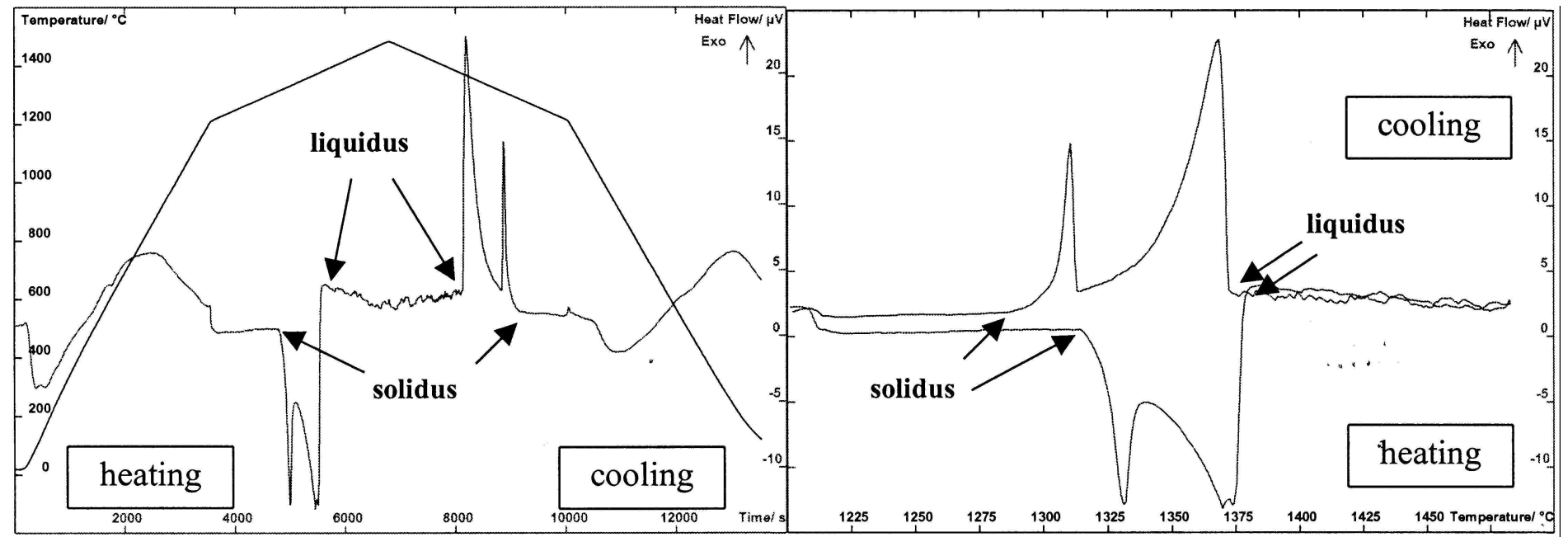

Figure 2 Example of DSC curve with two types of presentation (here : Alloy B)

Table 2 Solidus and Liquidus Temperatures by DSC Measurements

\begin{tabular}{|l|c|c|}
\hline Alloys & T solidus $\left({ }^{\circ} \mathbf{C}\right)$ & T liquidus $\left({ }^{\circ} \mathbf{C}\right)$ \\
\hline Alloy A & $1298 \pm 14$ & $1399 \pm 11$ \\
\hline Alloy B & $1301 \pm 15$ & $1377 \pm 4$ \\
\hline Alloy C & $1302 \pm 6$ & $1374 \pm 5$ \\
\hline
\end{tabular}

\section{Microstructure after 100 hours at High Temperature}

The BSE images of the three alloys after 100 hours at 1000,1100 and $1200^{\circ} \mathrm{C}$ are shown in Fig. 3. The initial microstructures after solidification were replaced by new ones, more corresponding to the equilibrium state. Densities of primary carbides has evolved, notably at the highest temperature. Indeed less carbides are present in each alloy after exposure at $1200^{\circ} \mathrm{C}$ and they are become rounder. At $1000^{\circ} \mathrm{C}$ and $1100^{\circ} \mathrm{C}$, the density of the interdendritic carbide network did not sensibly evolve. Alloy A lost almost all their tantalum carbides (and completely at $1200^{\circ} \mathrm{C}$ ) while no TaC carbides are visible in Alloy B. The surface fraction of tantalum carbides also decreased for Alloy $\mathrm{C}$ during exposure to high temperature. This partial or total disappearance of tantalum carbides is probably due to the chemical homogenization of the whole alloy when exposed to high temperature. Indeed one can think that tantalum was continuously rejected ahead the solidification front. The high local tantalum content obtained in the last zones to solidify promoted the formation of a higher TaC volume in grain 
boundaries than it could be predicted from the general chemical composition. Alloy B is a very good example to illustrate that tantalum carbides which appeared during solidification, have totally disappeared after high temperature exposure. Thereafter, 100 hours being a time long enough for all the temperatures used to achieve a total homogenization, the new microstructures should be very close to the equilibrium state corresponding to the alloys compositions. One can also note that finer secondary chromium carbides appeared in matrix, mainly near grain boundaries for $1000^{\circ} \mathrm{C}$ and sometimes for $1100^{\circ} \mathrm{C}$. Concerning the composition of the carbides, WDS microanalysis showed that white carbides were TaC. Chromium carbides were mainly $\mathrm{M}_{23} \mathrm{C}_{6}$ at $1000^{\circ} \mathrm{C}$ and $\mathrm{M}_{7} \mathrm{C}_{3}$ at $1200^{\circ} \mathrm{C}$ for all the alloys. For Alloy A and Alloy B the two types coexist at $1100^{\circ} \mathrm{C}$ since their two $\%_{\mathrm{at}} \mathrm{Cr} / \%_{\mathrm{at}} \mathrm{C}$ ratios were found.

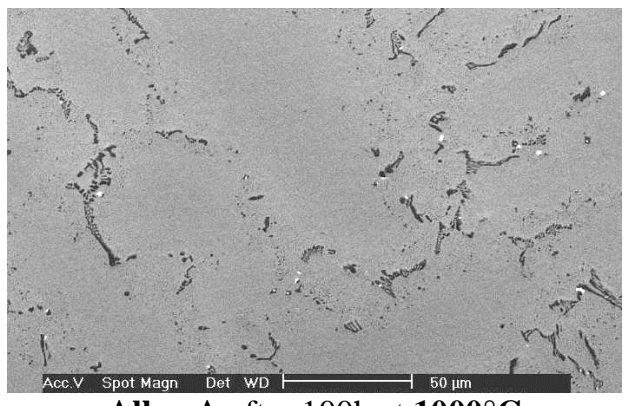

Alloy A after $100 \mathrm{~h}$ at $\mathbf{1 0 0 0}^{\circ} \mathbf{C}$

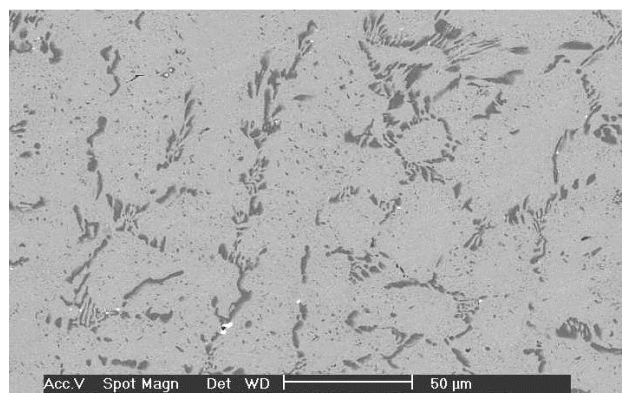

Alloy B after $100 \mathrm{~h}$ at $\mathbf{1 0 0 0}^{\circ} \mathbf{C}$

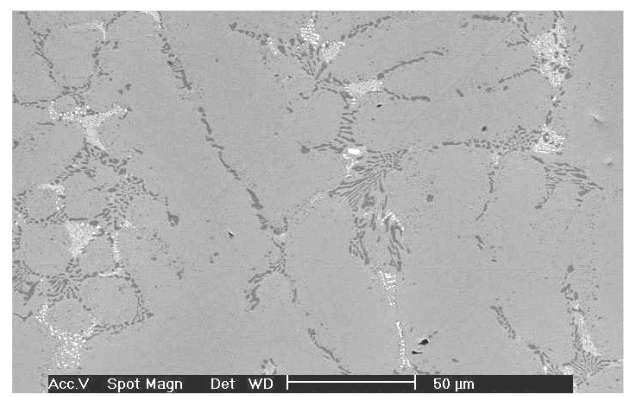

Alloy $\mathbf{C}$ after $100 \mathrm{~h}$ at $\mathbf{1 0 0 0}^{\circ} \mathbf{C}$

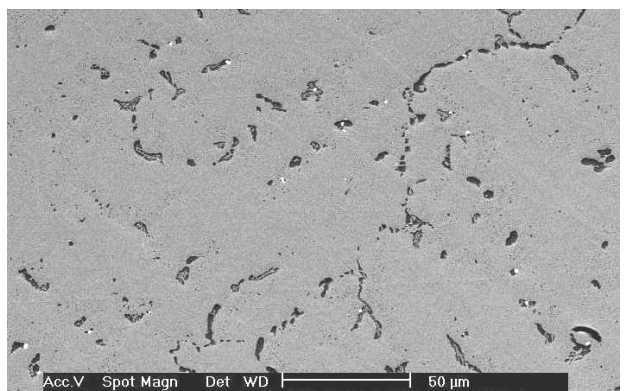

Alloy A after $100 \mathrm{~h}$ at $\mathbf{1 1 0 0}^{\circ} \mathbf{C}$

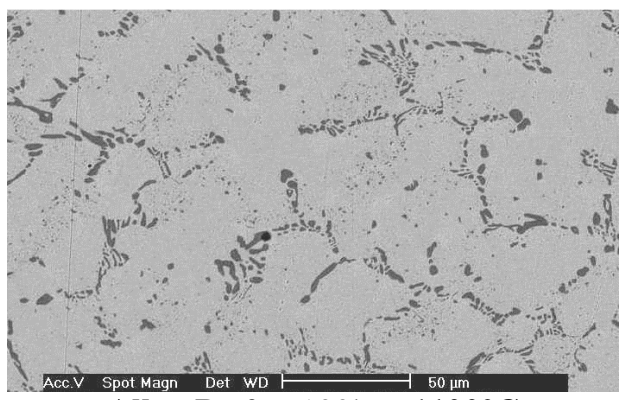

Alloy B after $100 \mathrm{~h}$ at $\mathbf{1 1 0 0}^{\circ} \mathbf{C}$

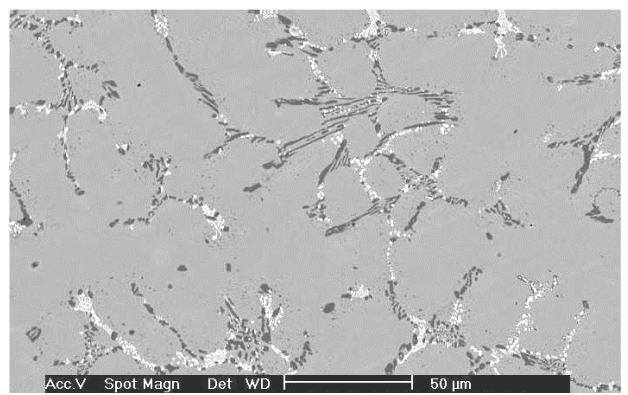

Alloy $\mathbf{C}$ after $100 \mathrm{~h}$ at $\mathbf{1 1 0 0}^{\circ} \mathbf{C}$

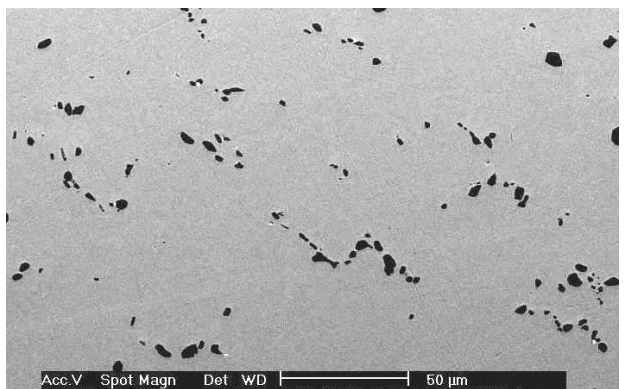

Alloy A after $100 \mathrm{~h}$ at $\mathbf{1 2 0 0}^{\circ} \mathbf{C}$

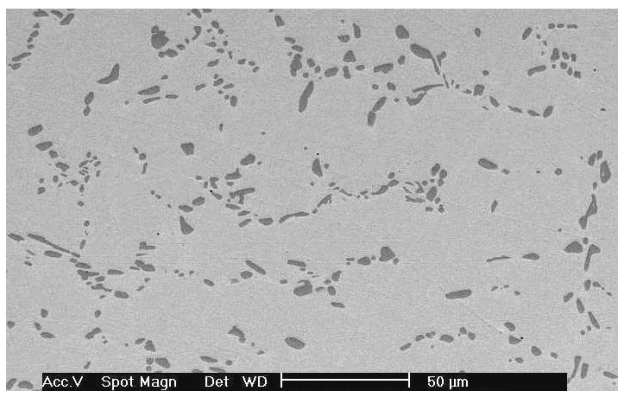

Alloy B after $100 \mathrm{~h}$ at $\mathbf{1 2 0 0}^{\circ} \mathrm{C}$

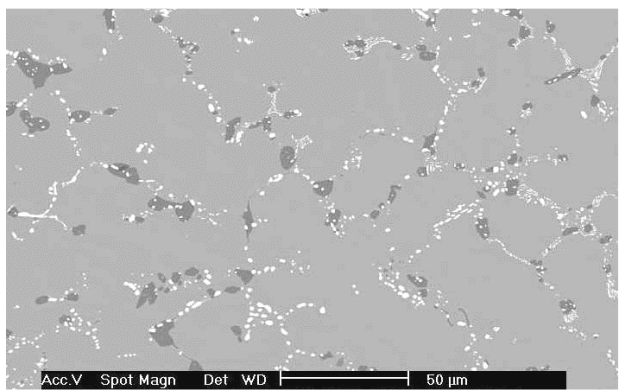

Alloy $\mathbf{C}$ after $100 \mathrm{~h}$ at $\mathbf{1 2 0 0}^{\circ} \mathrm{C}$

Figure 3 Microstructures of the three alloys after 100 hours at 1000,1100 and $1200{ }^{\circ} \mathrm{C}$ (BSE images)

Table 3 show the results of surface fraction measurements of the three alloys after the three high temperature exposures. Concerning the chromium carbides, the colors of $\mathrm{M}_{23} \mathrm{C}_{6}$ and $\mathrm{M}_{7} \mathrm{C}_{3}$ were almost the same and it was not possible to distinguish them from one another, therefore to measure their surface fractions separately. Thus we just considered the sum of the two surface (or volume) fractions. The uncertainties are defined by the average value of five pictures and the standard deviation. 
Table 3 Carbides Volume Fractions determined from Image Analysis Measurements

\begin{tabular}{|c|c|c|c|c|c|c|}
\hline \multirow{2}{*}{$\begin{array}{c}\text { volume } \\
\text { fractions } \\
(\%)\end{array}$} & Alloy A & Alloy B & Alloy C & Alloy A & Alloy B & Alloy C \\
\cline { 2 - 7 } & $2.44 \pm 0.49$ & $6.17 \pm 0.40$ & $3.71 \pm 0.49$ & $0.02 \pm 0.01$ & 0 & $2.93 \pm 0.13$ \\
\hline $1200^{\circ} \mathrm{C}$ & $2.66 \pm 0.47$ & $7.04 \pm 1.05$ & $7.00 \pm 1.16$ & $0.02 \pm 0.01$ & 0 & $3.48 \pm 0.73$ \\
\hline $1100^{\circ} \mathrm{C}$ & $3.68 \pm 0.86$ & $7.09 \pm 0.83$ & $7.74 \pm 0.69$ & $0.06 \pm 0.02$ & $0.06 \pm 0.03$ & $2.12 \pm 0.73$ \\
\hline $1000^{\circ} \mathrm{C}$ & & & & & & \\
\hline
\end{tabular}

\section{Matrix chemical composition}

Table 4 displays the chromium and tantalum contents determined by spot EDS analysis in the matrix of each alloy after the three high temperature exposures. The uncertainties are defined by the average value of five EDS results and the standard deviation.

For the three alloys, it appears that the majority of chromium remained in solid solution in the matrix while the other chromium atoms formed the interdendritic carbides. The matrix of Alloy A and Alloy B almost contain all the tantalum atoms while the matrix of Alloy $\mathrm{C}$ does not because of the presence of tantalum carbides.

Table 4 Matrix Cr and Ta Contents determined by Spot EDS Analysis

\begin{tabular}{|c|c|c|c|c|c|c|}
\hline \multirow{2}{*}{$\begin{array}{c}\text { Matrix } \\
\text { compositions } \\
(\% \text { wt }\end{array}$} & \multicolumn{3}{|c|}{ Matrix Cr content } & \multicolumn{3}{c|}{ Matrix Ta content } \\
\cline { 2 - 7 } & Alloy A & Alloy B & Alloy C & Alloy A & Alloy B & Alloy C \\
\hline $1200^{\circ} \mathrm{C}$ & $29.35 \pm 0.57$ & $28.10 \pm 0.33$ & $28.88 \pm 0.23$ & $2.04 \pm 0.32$ & $2.78 \pm 0.16$ & $2.99 \pm 0.20$ \\
\hline $1100^{\circ} \mathrm{C}$ & $28.13 \pm 0.44$ & $26.66 \pm 0.20$ & $27.25 \pm 0.05$ & $2.39 \pm 0.35$ & $2.70 \pm 0.09$ & $4.22 \pm 0.12$ \\
\hline $1000^{\circ} \mathrm{C}$ & $29.18 \pm 0.37$ & $27.46 \pm 0.10$ & $27.60 \pm 0.59$ & $2.38 \pm 0.37$ & $2.40 \pm 0.07$ & $3.57 \pm 0.51$ \\
\hline
\end{tabular}

\section{Thermodynamic Calculation}

\section{Thermal Analysis Results}

Table 5 displays both the values calculated using the database and the measured values of solidus and liquidus temperatures. The three measured solidus temperatures are almost the same for the three alloys while the calculated solidus sensibly decreases between Alloy B and Alloy C. There is a good agreement between calculated and measured values, except for Alloy C. Concerning the liquidus temperatures, the measured values are all higher than those predicted, especially for Alloy $\mathrm{C}$ for which both the measured solidus and liquidus are noticeably higher than the calculated values. 
Table 5 Solidus and Liquidus Temperatures by DSC Measurements and Calculations

\begin{tabular}{|c|c|c|c|c|}
\hline \multirow{2}{*}{ Alloy } & \multicolumn{2}{|c|}{ T solidus $\left({ }^{\circ} \mathrm{C}\right)$} & \multicolumn{2}{c|}{ T liquidus $\left({ }^{\circ} \mathrm{C}\right)$} \\
\cline { 2 - 5 } & Calculation & DSC analysis & Calculation & DSC analysis \\
\hline \multirow{2}{*}{ Alloy A } & $\mathbf{1 3 0 3}$ & $1298 \pm 14$ & $\mathbf{1 3 7 7}$ & $1399 \pm 11$ \\
\hline \multirow{2}{*}{ Alloy B } & $\mathbf{1 2 9 9}$ & $1301 \pm 15$ & $\mathbf{1 3 6 0}$ & $1377 \pm 4$ \\
\hline \multirow{2}{*}{ Alloy C } & $\mathbf{1 2 8 0}$ & $1302 \pm 6$ & $\mathbf{1 3 4 6}$ & $1374 \pm 5$ \\
\hline
\end{tabular}

\section{Microstructure after 100 hours at High Temperature}

Table 6 shows the calculated and the measured volume fractions of carbides of the alloys for the three temperatures. There is a good agreement between calculations and experiments for Alloy A. Indeed the nature of the predicted chromium carbides well corresponds to WDS microanalysis results $\left(\mathrm{M}_{23} \mathrm{C}_{6}\right.$ for $1000^{\circ} \mathrm{C}$, mix of $\mathrm{M}_{23} \mathrm{C}_{6}$ and $\mathrm{M}_{7} \mathrm{C}_{3}$ for $1100^{\circ} \mathrm{C}$ and only $\mathrm{M}_{7} \mathrm{C}_{3}$ for $1200^{\circ} \mathrm{C}$ ), and the calculated values of volume fractions remain inside the experimental ranges. One just can note that traces of tantalum carbides were seen in samples while this phase does not appear according to the calculation.

Table 6 Calculated and Experimental Carbides Volume Fractions for Alloy A, Alloy B and Alloy C

\begin{tabular}{|c|c|c|c|c|}
\hline \multirow{2}{*}{$\begin{array}{c}\text { Alloys } \\
\text { Temp }\left({ }^{\circ} \mathrm{C}\right)\end{array}$} & \multicolumn{2}{|c|}{ volume fraction of chromium carbides (\%) } & \multicolumn{2}{|c|}{ volume fraction of tantalum carbides (\%) } \\
\hline & Calculation & Image analysis & Calculation & Image analysis \\
\hline $\begin{array}{c}\text { Alloy A } \\
1200 \\
\end{array}$ & $2.41 * * *$ & $2.44 \pm 0.49$ & $\mathbf{0}$ & $0.02 \pm 0.01$ \\
\hline $\begin{array}{c}\text { Alloy A } \\
1100 \\
\end{array}$ & $2.64 * *$ & $2.66 \pm 0.47$ & $\mathbf{0}$ & $0.02 \pm 0.01$ \\
\hline $\begin{array}{c}\text { Alloy A } \\
1000 \\
\end{array}$ & $4.25 *$ & $3.68 \pm 0.86$ & $\mathbf{0}$ & $0.06 \pm 0.02$ \\
\hline $\begin{array}{c}\text { Alloy B } \\
1200\end{array}$ & $5.22 * * *$ & $6.17 \pm 0.40$ & $\mathbf{0}$ & 0 \\
\hline $\begin{array}{c}\text { Alloy B } \\
1100\end{array}$ & $6.11 * *$ & $7.04 \pm 1.05$ & $\mathbf{0}$ & 0 \\
\hline $\begin{array}{c}\text { Alloy B } \\
1000 \\
\end{array}$ & $6.89 *$ & $7.09 \pm 0.83$ & $\mathbf{0}$ & $0.06 \pm 0.03$ \\
\hline $\begin{array}{c}\text { Alloy C } \\
1200\end{array}$ & $5.25 * * *$ & $3.71 \pm 0.49$ & $\mathbf{0}$ & $2.93 \pm 0.13$ \\
\hline $\begin{array}{c}\text { Alloy C } \\
1100\end{array}$ & $8.52 *$ & $7.00 \pm 1.16$ & $\mathbf{0}$ & $3.48 \pm 0.73$ \\
\hline $\begin{array}{c}\text { Alloy C } \\
1000 \\
\end{array}$ & $8.69 *$ & $7.74 \pm 0.69$ & $\mathbf{0}$ & $2.12 \pm 0.73$ \\
\hline
\end{tabular}

$*$ : only $\mathrm{M}_{23} \mathrm{C}_{6}, * * *$ : only $\mathrm{M}_{7} \mathrm{C}_{3}$,

** : $0.59 \% \mathrm{M}_{23} \mathrm{C}_{6}$ and $2.18 \% \mathrm{M}_{7} \mathrm{C}_{3}$ (Alloy A) and $2.02 \% \mathrm{M}_{23} \mathrm{C}_{6}$ and $4.09 \% \mathrm{M}_{7} \mathrm{C}_{3}$ (Alloy B) 
Experimental measurements and calculation results also show a good agreement for Alloy B. No tantalum carbides are predicted nor observed, and the presence of $\mathrm{M}_{23} \mathrm{C}_{6}$ and/or $\mathrm{M}_{7} \mathrm{C}_{3}$ is also correctly given by calculations depending on temperature. The volume fraction of carbides is higher for Alloy B than for Alloy A because of a higher carbon content of Alloy B.

For Alloy C, great differences occurred between calculation and observation. The calculations predicted the presence of chromium carbides but not the $\mathrm{TaC}$ phase while significant amounts of tantalum carbides were observed in Alloy $\mathrm{C}$ samples after exposure at all temperatures. Even after 100 hours at $1200^{\circ} \mathrm{C}$, although the morphologies of all carbides significantly evolved, both chromium carbides and tantalum carbides are still presents with significant volume fractions.

\section{Matrix chemical composition}

For Alloy A there is a good agreement between calculations and experience since the calculated values often are inside the experimental ranges. For Alloy B there is also a good correspondence between calculation and experimental results even if calculated chromium content are slightly higher than the EDS results. Tantalum contents are almost strictly equals, except for $1000^{\circ} \mathrm{C}$ : for this temperature some small tantalum carbides, still existing in the microstructure after 100 hours, can be responsible of the lower real tantalum content of the matrix than predicted.

Table 7 Calculated and Experimental Matrix Cr and Ta Contents for Alloy A, Alloy B and Alloy C

\begin{tabular}{|c|c|c|c|c|}
\hline \multirow{2}{*}{$\begin{array}{c}\text { Matrix } \\
\text { compositions } \\
\left(\%_{\mathrm{wt}}\right)\end{array}$} & \multicolumn{2}{|c|}{ Matrix Cr content } & \multicolumn{2}{|c|}{ Matrix Ta content } \\
\hline & Calculation & EDS analysis & Calculation & EDS analysis \\
\hline $\begin{array}{c}\text { Alloy A } \\
1200\end{array}$ & 29.80 & $29.35 \pm 0.57$ & 2.08 & $2.04 \pm 0.32$ \\
\hline $\begin{array}{c}\text { Alloy A } \\
1100\end{array}$ & 29.63 & $28.13 \pm 0.44$ & 2.09 & $2.39 \pm 0.35$ \\
\hline $\begin{array}{c}\text { Alloy A } \\
1000 \\
\end{array}$ & 28.95 & $29.18 \pm 0.37$ & 2.11 & $2.38 \pm 0.37$ \\
\hline $\begin{array}{c}\text { Alloy B } \\
1200\end{array}$ & 29.38 & $28.10 \pm 0.33$ & 2.77 & $2.78 \pm 0.16$ \\
\hline $\begin{array}{c}\text { Alloy B } \\
1100\end{array}$ & 28.98 & $26.66 \pm 0.20$ & 2.79 & $2.70 \pm 0.09$ \\
\hline $\begin{array}{c}\text { Alloy B } \\
1000\end{array}$ & 27.74 & $27.46 \pm 0.10$ & 2.86 & $2.40 \pm 0.07$ \\
\hline $\begin{array}{c}\text { Alloy C } \\
1200\end{array}$ & 28.06 & $28.88 \pm 0.23$ & 5.68 & $2.99 \pm 0.20$ \\
\hline $\begin{array}{c}\text { Alloy C } \\
1100 \\
\end{array}$ & 26.57 & $27.25 \pm 0.05$ & 5.84 & $4.22 \pm 0.12$ \\
\hline $\begin{array}{c}\text { Alloy C } \\
1000\end{array}$ & 26.32 & $27.60 \pm 0.59$ & 5.84 & $3.57 \pm 0.51$ \\
\hline
\end{tabular}

For Alloy $\mathrm{C}$ great differences exist between calculations and EDS measurements, but they are in accordance with the differences seen earlier between the predicted and observed microstructures. Indeed, real chromium contents are slightly higher than the calculated values because of the presence of tantalum carbides in samples which lead to a matrix volume fraction slightly lower for a nearly same chromium quantity. Concerning tantalum, the matrix Ta contents are higher for calculation than the measured since a significant amount of TaC carbides is present in the Alloy $\mathrm{C}$ after exposure at all three temperatures. 


\section{Discussion}

For Alloy A and Alloy B, experimental observations and measurements appeared to be in good agreement with calculations performed using our database. Indeed the two ways lead to very similar results about the number and the natures of the present phases, their volume fractions and the chemical composition of the matrix. On the contrary, for Alloy $\mathrm{C}$, the experiment shows a significant amount of tantalum carbides even after high temperature exposure for a long time while the calculations predict the presence of chromium carbides alone.

It is true that the microstructural observations showed that tantalum containing Ni-base alloys seem to contain not so many $\mathrm{TaC}$ carbides as Co-base alloys for the same carbon, chromium and tantalum contents [10]. Indeed, for example, a Co-9\% Ni-28\%Cr-6\% Ta (weight percent) alloys contains only TaC carbides, the volume fraction of which is $5.4 \%$ at $1200^{\circ} \mathrm{C}$. This different behavior of the Ni-base alloys is found again with thermodynamic calculations, but there it is stronger and does not correspond very well to reality. However the same tendency is predicted and can be stated by drawing a $\%_{\mathrm{wt}} \mathrm{Ni}-\mathrm{T}$ diagram.

Such a diagram, drawn for Co-xNi-30Cr-0.4C-6Ta $\left(\%_{\text {wt }}\right)$ with $\mathrm{x}$ varying from a 0 to $60 \%_{\mathrm{wt}}$ (as is to say from a Ni-less Co-base alloy to a Ni-base one) is given by Fig. 4. This one allows us to confirm that a microstructure constituted by two phases, matrix and $\mathrm{TaC}$ carbides, can occur in Co-base alloys, even they contain some nickel. Let us remind that less than $10 \%_{\mathrm{wt}} \mathrm{Ni}$ are useful and sufficient to stabilize practically the fcc form of the cobalt-base alloys matrix for most of the working temperatures of these alloys. But if the nickel content increases beyond $10 \%_{\mathrm{wt}} \mathrm{Ni}$ (a limit which depends of the considered temperature $\mathrm{T}$ ), $\mathrm{M}_{7} \mathrm{C}_{3}$ or $\mathrm{M}_{23} \mathrm{C}_{6}$ (nature also depending of $\mathrm{T}$ ) appear and their weight fraction increase while the TaC fraction decreases. Beyond the barrier of $50 \% \%_{\mathrm{wt}} \mathrm{Ni}, \mathrm{TaC}$ cannot exist in the microstructure. Then, according to calculations, the presence of stable $\mathrm{TaC}$ is not possible in Nickel-base alloys containing $30 \%{ }_{\mathrm{wt}} \mathrm{Cr}, 0.4 \%_{\mathrm{wt}} \mathrm{C}$ and $6 \%_{\mathrm{wt}} \mathrm{Ta}$.

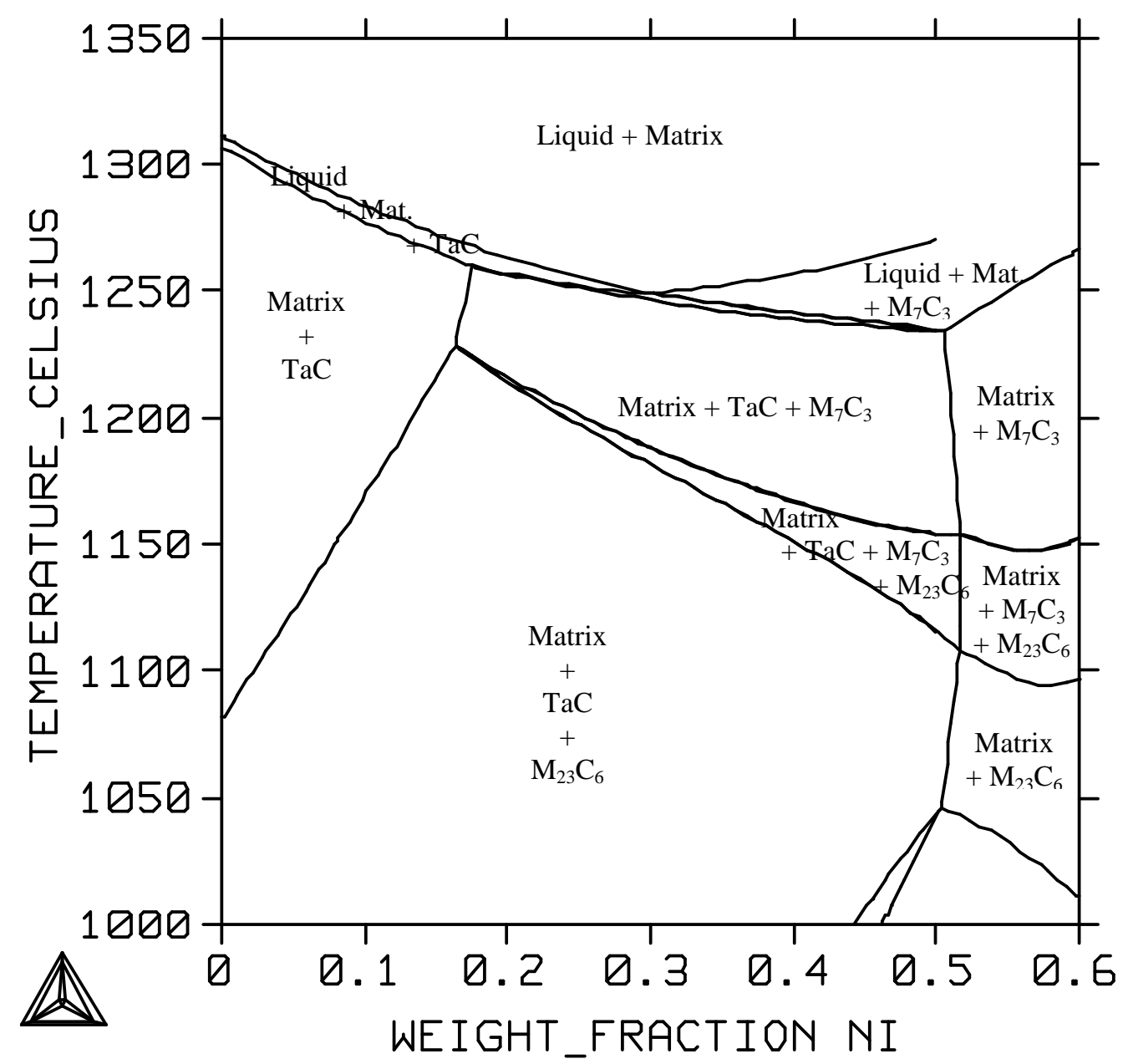

Figure 4 Diagram describing the microstructure dependence of the Ni content for a Co-xNi-30Cr-0.4C-6Ta with a special look at TaC carbides 
This disagreement suggests two possibilities. On the one hand Alloy $\mathrm{C}$ did not reach its stable state after 100 hours and needed more time for that. On the other hand, our database in not yet completed to allow very good predictions in some cases. Indeed, only the descriptions of two ternary systems out four are used to construct the quaternary thermodynamic description.

The first hypothesis is not serious looking at the Alloys A and B which lost all their initial TaC carbides during the same exposures. Then, it appears that the database really needs to be improved (by addition of the C$\mathrm{Ni}-\mathrm{Ta}$ and $\mathrm{C}-\mathrm{Cr}-\mathrm{Ta}$ descriptions) for better calculations for nickel-rich alloys with high contents of carbon and tantalum.

\section{Conclusion}

This work bring microstructural data about the equilibrium states of three different tantalum containing Ni-base alloys for three high temperatures to which this family can be exposed in work conditions. Liquidus and solidus temperatures, volume fractions of each type of carbides, matrix chemical concentrations are now available for these alloys. These results can be used to evaluate new databases built for systems including Ni-Cr$\mathrm{C}$-Ta alloys. First tests performed on a database developed for Co-Ni-C-Cr-Ta systems showed that this one allows good predictions so that Ta remains less than 3\%. This study also showed that it is more difficult to obtain stable $\mathrm{TaC}$ carbides in Ni-base alloys than in Co-base alloys. Knowing that, it appeared that TaC carbides may not be chosen for strengthening Ni-base superalloys for high temperature service.

\section{References}

1. $\quad$ E. F. Bradley: Superalloys : A Technical Guide, ASM International, 1988.

2. C. T. Sims and W. C. Hagel: The Superalloys, John Wiley \& Sons, 1972.

3. Thermo-Calc version N: "Foundation for Computational Thermodynamics" Stockholm, Sweden, Copyright (1993, 2000). www.thermocalc.com

4. SGTE: "Scientific Group Thermodata Europe" database, update 1992. www.SGTE.org

5. $\quad$ K. Frisk and A. Fernandez Guillermet, J. Alloys and Compounds, 238 (1996) 167-179.

6. I. Ansara and M. Selleby, CALPHAD, 18 (1994) 99-107.

7. $\quad$ N. Dupin and I. Ansara, J. Phase Equilibria, 14 (1993) 451-456.

8. $\quad$ N. Dupin and I. Ansara, Z. Metallkd., 87 (1996) 555-561.

9. Handbook of Chemistry and Physics, $57^{\text {th }}$ edition (1976-1977)

10. P. Berthod, S. Michon, L. Aranda, S. Mathieu and J.C. Gachon, CALPHAD, 27 (2003) 353-359. 